\title{
Stability and Sensory Evaluation of an Innovative Antiaging Formulation Based on Marine Ingredients
}

\author{
Amanda Tavares Fortunato ${ }^{1}$ \\ https://orcid.org/0000-0003-1700-8976
}

Melissa Marques Gonçalves ${ }^{2}$

https://orcid.org/0000-0002-6524-2188

Guilherme Augusto Colusse ${ }^{3}$

https://orcid.org/0000-0001-7707-8672

\author{
Camila Benato Adonski ${ }^{1}$ \\ https://orcid.org/0000-0001-9427-9943
}

Bárbara Paula Borges ${ }^{1}$

https://orcid.org/0000-0001-9297-7772

Jaqueline Carneiro ${ }^{1,2^{\star}}$

https://orcid.org/0000-0002-2037-0215

${ }^{1}$ Autonomous University Center of Brazil - UNIBRASIL, Pharmacy Department, Curitiba, Paraná, Brazil; ${ }^{2}$ Federal University of Paraná, Pharmacy Department, Curitiba, Paraná, Brazil; ${ }^{3}$ Federal University of Paraná, Bioprocess Engineering and Biotechnology Department, Curitiba, Paraná, Brazil.

Editor-in-Chief: Paulo Vitor Farago

Associate Editor: Paulo Vitor Farago

Received: 2020.07.03; Accepted: 2020.12.18.

*Correspondence: profjaquelinec@gmail.com; Tel.: +55-42-999916383 (J.C.)

\section{HIGHLIGHTS}

- Marine environment has been an important source of cosmetic ingredients.

- Caviar extract (2\%) has scavenged $10.9 \% \pm 0.58$ of DPPH radical.

- Ca-alginate beads has been obtained successfully.

- Formulation showed good stability and sensory acceptance.

Abstract: The high consumption of antiaging cosmetics represents an outstanding opportunity for the development of new processes and attractive products in the cosmetic industry. Stability studies and sensory analyses are critical steps in the development process and production chain. Here we present a potential antiaging cosmetic product with innovative sensory characteristics. Caviar extract antioxidant properties were firstly evaluated by the DPPH method since it is an important mechanism against skin aging. Ca-alginate beads containing $2 \%$ of caviar extract and $0.2 \%$ of black pigment were prepared to obtain spheres similar to caviar. The beads were incorporated in a gel phase (hydroxyethylcellulose $2.5 \%$ ) containing $3 \%$ of dimethylaminoethanol. Stability was evaluated in different storage conditions (sunlight exposure, $5 \pm 2{ }^{\circ} \mathrm{C}$, $37 \pm 2{ }^{\circ} \mathrm{C}$ and r.t.) through the parameters: appearance, color and odor, $\mathrm{pH}(6-7)$, density (0.98-1.14 g. $\left.\mathrm{mL}^{-1}\right)$, centrifugation and average size. After approval by the Committee for Ethics in Research ( $\left.n^{\circ} 3.503 .061\right), 30$ volunteers tested the new formulation and answered a questionnaire. At $2 \%$, caviar extract was able to scavenge $10.9 \% \pm 0.58$ of DPPH radical. Formulations showed good stability after 90 days, even considering the average size $\left(7.47 \pm 0.41-8.4 \pm 0.65 \mathrm{~mm}^{2}\right) .90 \%$ of the sensory test participants reported that they would buy the new product. Therefore, the new product developed demonstrates a promising potential as an attractive cosmetic product. 
Keywords: formulation development; DMAE; sensory analysis; polymers; Ca-alginate beads.

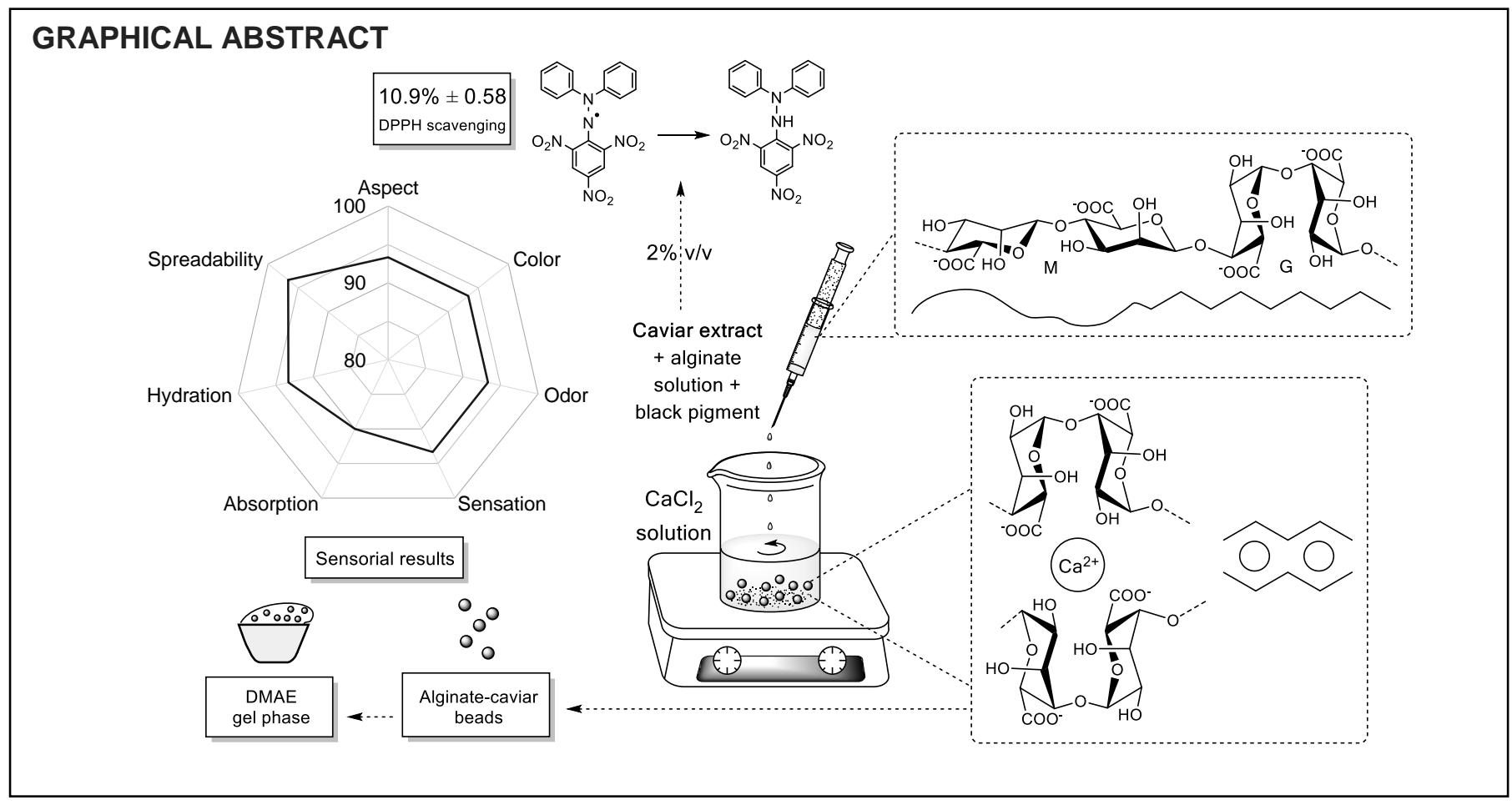

\section{INTRODUCTION}

The increase in life expectancy, growing of elderly global population, and higher expectations on looking young, are some of the factors that promote great interest in all aspects related to the aging process. In what concern to the cosmetic sector, the consumption of antiaging products is becoming more expressive and new ones are frequently launched to the market [1]. Cutaneous or skin aging is characterized by the progressive loss of structural integrity of skin that occurs due to intrinsic and extrinsic factors. Intrinsic aging is a physiological genetically determined process, which results in discrete dermal atrophy, thin wrinkles, and dry skin. External environmental factors, such as smoking, nutritional habits, pollution, and especially sunlight exposure, promote a more aggressive scenario called extrinsic aging. The results are irregular pigmentation, rough wrinkles, thickening of the cornified layer, elasticity loss, and higher risk of skin cancer [2-4].

There are several mechanisms proposed to explain skin aging and, possibly, it is a result of all of them. Undoubtedly, oxidative stress plays an important role in this process and chronic UV exposition, also called photoaging, produces even more reactive oxygen species (ROS). This fact makes antioxidants common on skincare formulations to enrich the endogenous cutaneous protection, which has a consistently attested efficacy for this purpose [2]. Despite antioxidant popularity, tocopherol and ascorbic acid are the most used in cosmetics, even with problems such as low stability, reflecting the lack of innovative materials on this field [5].

The green consumption trend and the growing demand for products made with natural ingredients are confronting the environmental impact caused by the cosmetic industry, stimulating companies to incorporate natural origin agents on formulations [6,7]. The exploration of the vast marine biodiversity has shown the potential to discover a wide range of active ingredients, making cosmetic companies interested. The application of algae and its derivatives, such as natural colorant or polysaccharides, in cosmetics is one of the most recurrent and versatile options, varying as the active ingredient, sensory adjuvant, or as a technological tool [8-10].

Moreover, in the past few years, cosmetic brands have been strongly investing in caviar-based products. Caviar consists of unfertilized salt-cured sturgeon eggs (Acipenser spp.) and is considered a luxury gastronomic delicacy. The strong interest of the food industry is related to its nutritional content, such as proteins, unsaturated fatty acids [11], vitamins, and minerals, which makes caviar to be considered for cosmetic purposes as well $[12,13]$. Also occurring in fish like sardines and salmon, dimethylaminoethanol (DMAE) is a substance frequently used with antiaging appeal due to several possible mechanisms that are constantly investigated [14-17]. 
Within this scenario, besides the need to invest in natural raw materials, cosmetic product developers are more than ever investing in new sensory technologies to survive in this competitive market. Therefore, sensory assessments turned out to be an important tool in formulation development to guarantee product success [18]. Here, we have developed and studied an innovative cosmetic formulation using marine ingredients, highlighting its antiaging potential. In addition, a sensory evaluation was conducted with untrained consumers.

\section{MATERIAL AND METHODS}

\section{Materials}

The following materials were used to perform this study: caviar extract (InfinityPharma $\left.{ }^{\circledR}\right)$; DPPH (1,1diphenyl-2-picrylhydrazyl) (SigmaAldrich ${ }^{\circledR}$ ); sodium alginate (Dinâmica ${ }^{\circledR}$, low viscosity); black pigment (117260 Colorona ${ }^{\circledR}$ Mica Black Merck); DMAE (dimethylaminoethanol) (SigmaAldrich ${ }^{\circledR}$ ); phenoxyethanol and caprylyl glycol (Optiphen ${ }^{\circledR}$ ); spectrophotometer Novainstruments ${ }^{\circledR}$ 2000, Peristaltic Pump P-1 (Pharmacia Biotech).

\section{Free radical scavenging potential}

The antioxidant potential of caviar extract (InfinityPharma ${ }^{\circledR}$ ) was evaluated through DPPH (1,1-diphenyl2-picrylhydrazyl) radical scavenging method with some modifications [19]. Serial dilutions were performed to obtain sample concentrations varying between $0-100 \%(\mathrm{v} / \mathrm{v})$ in methanol. In a test tube, $200 \mu \mathrm{L}$ of DPPH solution $\left(0.5 \mathrm{mmol} . \mathrm{L}^{-1}\right.$ in methanol) and $800 \mu \mathrm{L}$ of each solution were mixed and incubated at $25{ }^{\circ} \mathrm{C}$ for 30 min, protected from light. After that, sample absorbances were measured using a spectrophotometer Novainstruments ${ }^{\circledR} 2000$ at $517 \mathrm{~nm}$. Sample dilutions were used as blank and methanol plus DPPH as negative control. Moreover, ascorbic acid was used as positive control. Results indicated the percentage of DPPH scavenging. The experiment was performed in triplicate and the results were expressed as the mean \pm SD (standard deviation).

\section{Formulation study}

Ca-alginate beads were obtained according to De-Bashan and coauthors with some modifications [20]. Briefly, sodium alginate (Dinâmica ${ }^{\circledR}$, low viscosity) solution $(0.8 \%, 1.0 \%, 1.5 \%)$ containing $2 \%(\mathrm{v} / \mathrm{v})$ of caviar extract and $0.2 \%$ of black pigment (117260 Colorona ${ }^{\circledR}$ Mica Black Merck) was dropped using a Peristaltic Pump P-1 (Pharmacia Biotech) with a flow rate of $270 \mathrm{~mL} \mathrm{~h}^{-1}$ into a $5 \% \mathrm{CaCl}_{2}$ solution. The suspension was stirred to prevent beads aggregation. The Ca-alginate beads were stabilized in $\mathrm{CaCl}_{2}$ solution for 30 min, and then rinsed twice in $0.85 \% \mathrm{NaCl}$ solution and once in distilled water.

Four formulations were studied for the external phase using two gelling polymers: hydroxyethylcellulose, Natroso $\mathrm{I}^{\circledR}(2.5$ and $3.0 \%)$, and carbomer, Carbopol ${ }^{\circledR}(2.5$ and $5.0 \%)$. Polymers were firstly dispersed in water (qsp. 100\%) under stirring (and heating for Carbopol $^{\circledR}$ ). Then, $1 \%$ of phenoxyethanol and caprylyl glycol (Optiphen ${ }^{\circledR}$ ) and $5 \%$ of propylene glycol were poured under mechanical stirring; pH was correct using triethanolamine (qs. pH 7-8). DMAE (SigmaAldrich $\left.{ }^{\circledR}\right)(3 \%)$ was then added to the formulation chosen, which was used for $\mathrm{Ca}$-alginate beads incorporation (2:1).

\section{Stability study}

The final formulation was stored in glass vessels to be evaluated at $0,7,15,3060$ and 90 days, in different conditions: sunlight exposure, refrigerator $\left(5 \pm 2{ }^{\circ} \mathrm{C}\right)$, oven $\left(37 \pm 2{ }^{\circ} \mathrm{C}\right)$ and room temperature (r.t.). Organoleptic evaluation (appearance, color, and odor) and physicochemical characteristics ( $\mathrm{pH}$, density, and stability after centrifugation) were performed [21]. Centrifugation was done with $5 \mathrm{~g}$ of the product only at time zero (3000 rpm, $30 \mathrm{~min}$ ) (Centribio ${ }^{\circledR}$ ). $\mathrm{pH}$ was determined using colorimetric indicator strips (MColorpHast ${ }^{\mathrm{TM}}$ ) and density was done using a metal pycnometer. The average size $\left(\mathrm{mm}^{2}\right)$ was determined at 0 and 90 days. To proceed with size determination, photos from the spheres were taken and evaluated using the software Image $\mathrm{J}$ to calculate the average size of each sphere. Average size experiments were performed in triplicate $(n=10)$ and the results were expressed as the mean \pm SD (standard deviation). Significant differences were determined using a one-way analysis of variance (ANOVA). Differences between mean values were tested using Tukey's test, and averages followed by the same letter do not significantly differ $(p<.05)$. 
Sensory analysis was performed with 30 volunteers aged 18-50 years (15 male and 15 female). The volunteers that reported allergic sensitivity to any component of the formulation and people with visible dermatological conditions were excluded from this study. All the selected volunteers were informed previously about the whole procedure before signing the consent form. This study protocol was previously filed and approved by the Committee for Ethics in Research (CEP), $n^{\circ} 3.503 .061$, according to legislation related to research involving humans. $5 \mathrm{~g}$ of the formulation was available to the volunteers that were oriented to apply on the back of the left hand in circular movements. Then, a questionnaire related to cosmetics consumption behavior, perceptions, and product opinion was made available [22].

\section{RESULTS}

\section{Free radical scavenging potential}

In this study, we evaluated hydrosoluble caviar extract free radical scavenging capacity through the DPPH method. Different extract concentrations were evaluated in a range of $0-100 \% \mathrm{v} / \mathrm{v}$. It was noticed that at $2 \% \mathrm{v} / \mathrm{v}$, the concentration used in this study formulation, caviar extract was able to scavenge $10.9 \% \pm 0.58$ of DPPH free radical.

\section{Formulation study}

Caviar extract was encapsulated in Ca-alginate beads to achieve sensorial characteristics similar to caviar, which were added to a gel formulation containing dimethylaminoethanol (DMAE) (Figure 1).

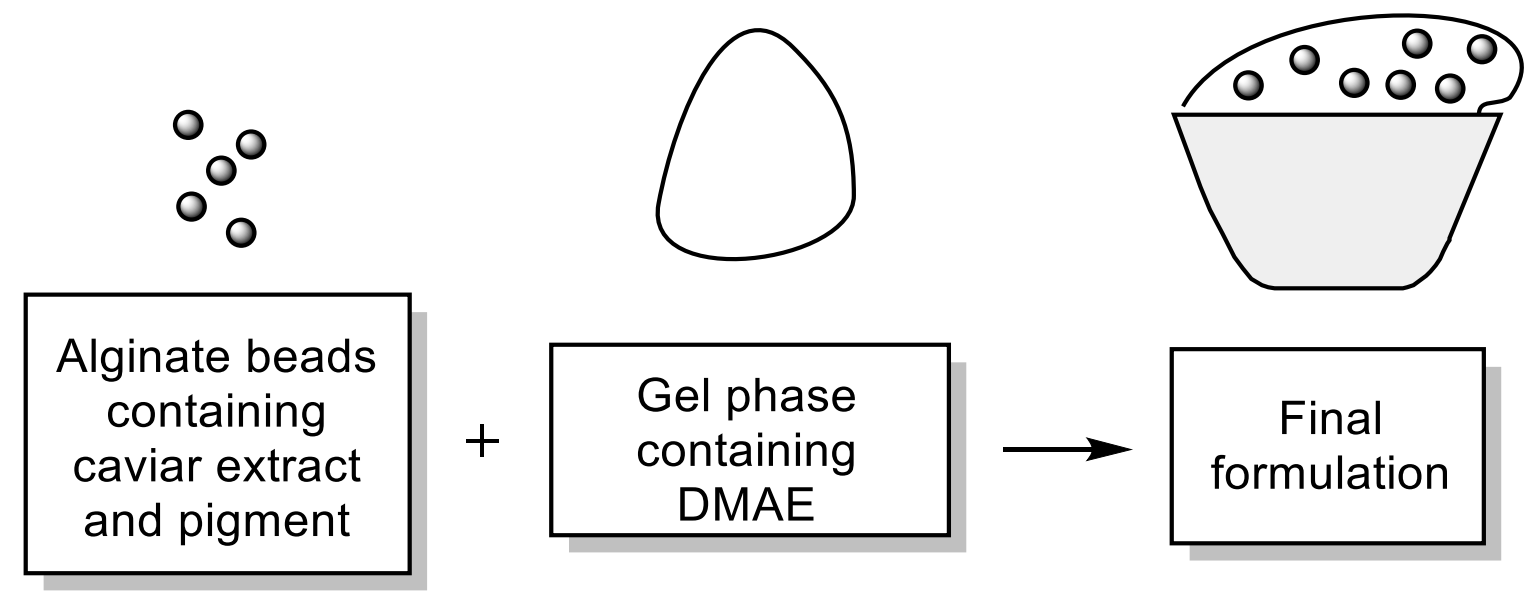

Figure 1. Experimental strategy to obtain final formulation.

Among the different sodium alginate concentrations tested, we notice that polymer concentration influences the final beads aspect and the ideal concentration found was $1.0 \% \mathrm{w} / \mathrm{v}$. Caviar extract and black pigment were mixed to alginate solution prior to dropping so it could be encapsulated into the jelly sphere. Visually, it was not possible to observe the colored extract nor black pigment residues into $\mathrm{CaCl}_{2}$ solution that indicates full encapsulation.

The gel phase containing DMAE was studied with different polymers commonly used in cosmetics, varying their concentrations [23,24]. Hydroxyethylcellulose at $2.5 \%$ was the condition chosen because it presented a desirable consistency to maintain the beads in suspension. After incorporation, the final formulations presented an aspect similar to caviar (Figure 2). 


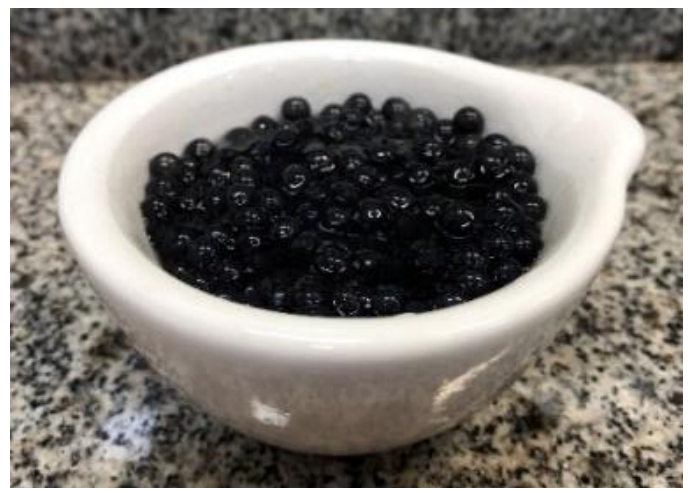

Figure 2. Final caviar-like formulation obtained.

\section{Stability study}

A 90 days stability study was performed to observe the formulation behavior towards stress storage conditions. The formulation remained stable, with intact $\mathrm{Ca}$-alginate beads after the 30 minutes centrifugation test. Results obtained for all parameters evaluated on different conditions and periods are presented in Table 1.

Table 1. Stability study data obtained for the formulation tested

\begin{tabular}{|c|c|c|c|c|c|c|c|}
\hline \multirow{2}{*}{ Parameter } & \multirow{2}{*}{ Condition } & \multicolumn{6}{|c|}{ Time (days) } \\
\hline & & 0 & 7 & 15 & 30 & 60 & 90 \\
\hline \multirow{4}{*}{$\begin{array}{c}\text { Organoleptic } \\
\text { characteristics }\end{array}$} & r.t. & + & + & + & + & + & + \\
\hline & light & + & + & + & + & + & + \\
\hline & $5 \pm 2{ }^{\circ} \mathrm{C}$ & + & \pm & \pm & \pm & \pm & \pm \\
\hline & $37 \pm 2^{\circ} \mathrm{C}$ & + & \pm & \pm & \pm & \pm & \pm \\
\hline \multirow{4}{*}{$\mathrm{pH}$} & r.t. & 6 & 7 & 7.5 & 6.5 & 6.5 & 6.5 \\
\hline & light & 6 & 6 & 7 & 7 & 7 & 7 \\
\hline & $5 \pm 2^{\circ} \mathrm{C}$ & 6 & 6 & 7 & 7 & 7 & 7 \\
\hline & $37 \pm 2^{\circ} \mathrm{C}$ & 6 & 6 & 6 & 6 & 6 & 6 \\
\hline \multirow{4}{*}{$\begin{array}{l}\text { Density } \\
\left(\text { g. } \mathrm{mL}^{-1}\right)\end{array}$} & r.t. & 0.98 & 1.03 & 1.11 & 1.03 & 1.05 & 1.09 \\
\hline & light & 0.98 & 1.02 & 1.11 & 1.10 & 1.09 & 1.10 \\
\hline & $5 \pm 2^{\circ} \mathrm{C}$ & 0.98 & 1.04 & 1.06 & 1.04 & 1.07 & 1.05 \\
\hline & $37 \pm 2{ }^{\circ} \mathrm{C}$ & 0.98 & 1.14 & 1.07 & 1.00 & 1.05 & 1.10 \\
\hline
\end{tabular}

No alteration (+), slightly altered $( \pm)$, altered (-), strongly altered (--).

Caviar-like formulation collected at days 0 and 90 were submitted to average size evaluation through Image $\mathrm{J}$ software to verify differences in size over stability time. The beads at day 0 presented an average size of $12.98 \pm 0.39^{\mathrm{a}} \mathrm{mm}^{2}$, whereas caviar-like formulation stored in the following conditions: sunlight exposure, refrigerator $\left(5 \pm 2{ }^{\circ} \mathrm{C}\right)$, oven $\left(37 \pm 2{ }^{\circ} \mathrm{C}\right)$ and room temperature, after 90 days, showed $8.07 \pm$ $0.58^{\mathrm{bc}}, 7.47 \pm 0.41^{\mathrm{c}}, 8.4 \pm 0.65^{\mathrm{b}}$ and $8.36 \pm 0.9^{\mathrm{b}} \mathrm{mm}^{2}$, respectively.

\section{Sensory analysis}

The formulation studied was made available for 30 volunteers, including men and women. In the first step of the questionnaire applied, we asked questions related to the customer's habits. It was observed that $77 \%$ of the volunteers use at least one cosmetic product daily. The sensory attributes evaluated were aspect, color, odor, sensation, absorption, hydration, and spreadability. The volunteers were guided to choose 
between 1 to 5 (horrible to great, respectively) which sensory experience they had with the formulation. As showed on the sensory map presented (Figure 3), all parameters evaluated showed good evaluation. As a final question about the possible product acquisition, $90 \%$ of the volunteers reported that they would buy it.

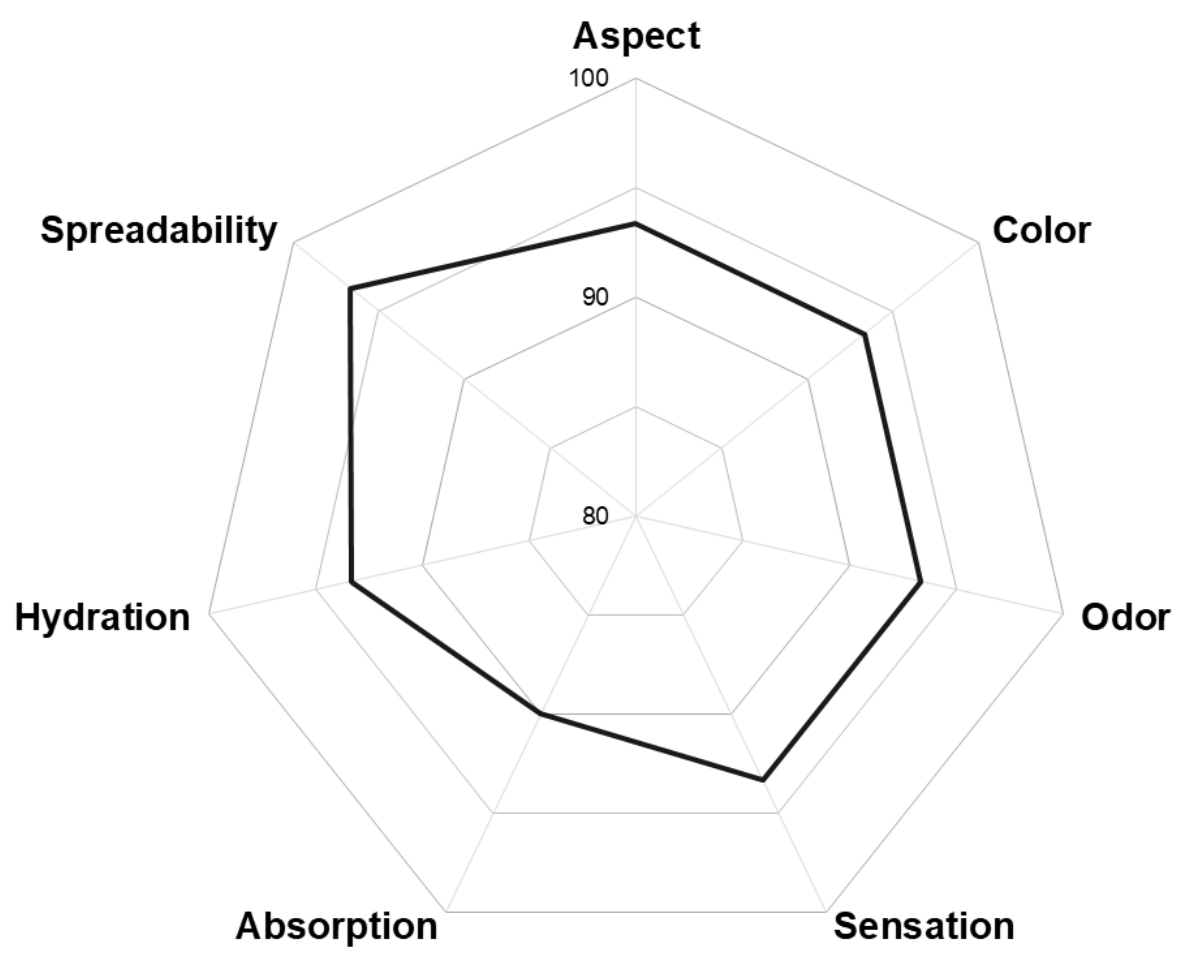

Figure 3. Sensory profile obtained using volunteers questionnaires

\section{DISCUSSION}

It is well known that the use of topical antioxidants is essential to prevent ROS damage on the skin. The most commonly used are tocopherol, ascorbic acid, their derivatives, and combinations. The main limitation to develop products with these compounds is their liability, which makes necessary the search for new antioxidant agents capable of maintaining activity, percutaneous absorption, and formulation integrity $[5,25]$. Caviar has been studied as an option of antiaging agents for its potential beneficial effects, such as antioxidant property, enhancement of the mRNA expression of type I procollagen, and upregulation of antioxidant genes $[12,26]$. DPPH scavenging activity presented an intrinsic relationship related to caviar extract concentration that not only provides an insight into the importance of marine derivatives in cosmetics but also demonstrates an option to incorporate natural compounds into breakthrough technologies.

The caviar-like formulation was obtained by exploring an interesting property observed for alginate. Alginate is a polysaccharide obtained from brown algae, composed of linear chains of mannuronic acid (M) and guluronic acid $(\mathrm{G})$ units [27]. In the presence of calcium ions, a strong complex called egg-box structure could be reached. Using a dropping technique it was possible to obtain spherical shape Ca-alginate beads $[28,29]$ (Figure 4). Alginate is frequently applied to carry and deliver a wide range of compounds for different applications. Other polysaccharides could also be explored to enrich formulation sustainability, performance, and marine appeal, by replacing the synthetic gelling polymer. 


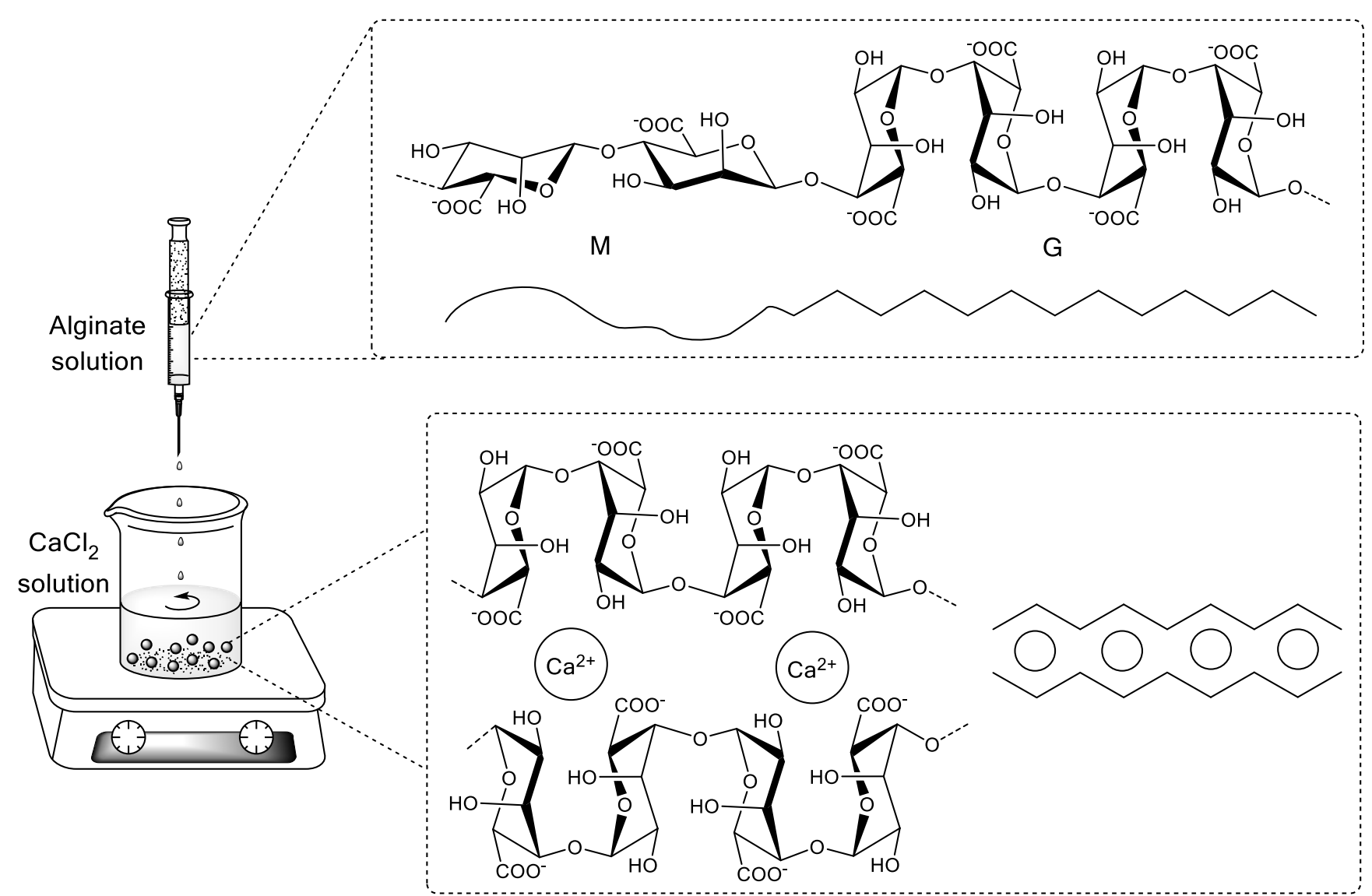

Figure 4. Schematic representation of the dropping technique performed and the formation of an egg-box structure

The development of a new cosmetic product includes several steps between initial research and the final commercial product. The stability study is important to better understand the physical chemistry properties, to ensure organoleptic attributes consistency and to detect any instability [30,31]. Critical parameters that determine cosmetic stability are temperature, $\mathrm{pH}$ variation, and light exposure. Samples remained stable throughout the study. $\mathrm{pH}$ determinations showed no significant alterations during the whole storage period, with $\mathrm{pH}$ values between 6.0 and 7.5, adequate for topic use. The slight alteration of organoleptic characteristics after day 7 , for refrigerator and oven samples, indicates that the better storage condition for this formulation is room temperature. All size results after 90 days stability presented significant differences when compared with average size from day 0 . This decrease could be explained by the Ca-alginate bead slightly disintegration, evidenced by the calcium ions loss started around 30 days after encapsulation [32]. Although the results showed a substantial difference in average size decrease over time, parameters such as organoleptic and physicochemical characteristics remained stable after 90 days.

Cosmetic companies need to constantly develop new products and improve their existing ones in order to stay ahead in a highly competitive market. In this context, consumer research is a key tool for product developers. Previous research showed that untrained consumers are able to provide relevant information about their perception using tools like questionnaires [18,22,33]. The high consumption pattern was highlighted by the questionnaire related to the customer's habits. Moreover, the product characteristics judged by the volunteers were positively evaluated and the majority declared that would buy it. Previous studies have been performed to establish relationships between in vitro efficacy, physicochemical characteristics, and others to sensory analyses, which reinforce the importance of this tool. Therefore, the new marine-based formulation has the potential to be explored as a new cosmetic product.

\section{CONCLUSION}

An antiaging cosmetic formulation with innovative sensory features has been developed. Caviar extract showed radical scavenging capacity, which is an important feature for antiaging products. Ca-alginate beads containing caviar extract were obtained with spherical shape and homogeneous size dispersion. Although differences in average size, formulation presented good stability during the accelerated stability study performed. Through the sensory analysis with 30 volunteers, it was possible to conclude that the new cosmetic product has a high potential for a new antiaging cosmetic product. To further evaluate the potential 
of the cosmetic formulation, future research might involve the optimization of caviar extract concentration addition as well as an in-depth study on the balance of the cutaneous microbiome.

Funding: This research received no external funding.

Conflicts of Interest: The authors declare no conflict of interest.

\section{REFERENCES}

1. Godic A. The role of stem cells in anti-aging medicine. Clin Dermatol [Internet]. 2019;37(4):320-5. Available from: https://doi.org/10.1016/j.clindermatol.2019.04.011

2. Zhang S, Duan E. Fighting against Skin Aging: The Way from Bench to Bedside. Cell Transplant. 2018;27(5):729_ 38.

3. Friedman O. Changes associated with the aging face. Facial Plast Surg Clin North Am. 2005;13(3):371-80.

4. Farage MA, Miller KW, Elsner P, Maibach HI. Intrinsic and extrinsic factors in skin ageing: A review. Int J Cosmet Sci. 2008;30(2):87-95.

5. Silva S, Ferreira M, Oliveira AS, Magalhães C, Sousa ME, Pinto M, et al. Evolution of the use of antioxidants in anti-ageing cosmetics. Int J Cosmet Sci. 2019;41(4):378-86.

6. Mellou F, Varvaresou A, Papageorgiou S. Renewable sources: applications in personal care formulations. Int J Cosmet Sci. 2019;41(6):517-25.

7. Sathasivam R, Ki JS. A review of the biological activities of microalgal carotenoids and their potential use in healthcare and cosmetic industries. Mar Drugs. 2018;16(1).

8. Guillerme JB, Couteau C, Coiffard L. Applications for marine resources in cosmetics. Cosmetics. 2017;4(3):1-15.

9. Venkatesan J, Anil S, Kim SK, Shim MS. Marine fish proteins and peptides for cosmeceuticals: A review. Mar Drugs. 2017;15(5):1-18.

10. Wang HMD, Chen CC, Huynh P, Chang JS. Exploring the potential of using algae in cosmetics. Bioresour Technol [Internet]. 2015;184:355-62. Available from: http://dx.doi.org/10.1016/j.biortech.2014.12.001

11. Caprino F, Moretti VM, Bellagamba F, Turchini GM, Busetto ML, Giani I, et al. Fatty acid composition and volatile compounds of caviar from farmed white sturgeon (Acipenser transmontanus). Anal Chim Acta. 2008;617(1-2):13947.

12. Marotta F, Polimeni A, Solimene U, Lorenzetti A, Minelli E, Jain S, et al. Beneficial modulation from a high-purity caviar-derived homogenate on chronological skin aging. Rejuvenation Res. 2012;15(2):174-7.

13. Wirth M, Kirschbaum F, Gessner J, Krüger A, Patriche N, Billard R. Chemical and biochemical composition of caviar from different sturgeon species and origins. Nahrung - Food. 2000;44(4):233-7.

14. Gabriela Malanga, Maria Belen Aguiar, Hugo D. Martinez, Susana Puntarulo. New Insights on Dimethylaminoethanol (DMAE) Features as a Free Radical Scavenger. Drug Metab Lett. 2012;6(1):54-9.

15. Liu S, Chen Z, Cai X, Sun Y, Zhao C, Liu F, et al. Effects of dimethylaminoethanol and compound amino acid on D-galactose induced skin aging model of rat. Sci World J. 2014;2014.

16. Gragnani A, Giannoccaro FB, Sobral CS, França JP, Ferreira LM. Dimethylaminoethanol affects the viability of human cultured fibroblasts. Aesthetic Plast Surg. 2007;31(6):711-8.

17. Grossman R. The role of dimethylaminoethanol in cosmetic dermatology. Am J Clin Dermatol. 2005;6(1):39-47.

18. Pensé-Lhéritier AM. Recent developments in the sensorial assessment of cosmetic products: A review. Int $J$ Cosmet Sci. 2015;37(5):465-73.

19. Kedare SB, Singh RP. Genesis and development of DPPH method of antioxidant assay. J Food Sci Technol. $2011 ; 48(4): 412-22$.

20. Bashan Y, Hernandez JP, Leyva LA, Bacilio M. Alginate microbeads as inoculant carriers for plant growthpromoting bacteria. Biol Fertil Soils. 2002;35(5):359-68.

21. Sharma Bora N, Mazumder B, Patowary P, Kishor S, Doma Bhutia Y, Chattopadhyay $P$, et al. Formulation development and accelerated stability testing of a novel sunscreen cream for ultraviolet radiation protection in high altitude areas. Drug Dev Ind Pharm [Internet]. 2019;45(8):1332-41. Available from: https://doi.org/10.1080/03639045.2019.1616750

22. Chowjarean V, Phiboonchaiyanan PP, Harikarnpakdee S, Tengamnuay P. A natural skin anti-ageing serum containing pseudobulb ethanolic extract of Grammatophyllum speciosum: a randomized double-blind, placebocontrolled trial. Int J Cosmet Sci. 2019;41(6):548-57.

23. Noreen A, Zia KM, Tabasum S, Khalid S, Shareef R. A review on grafting of hydroxyethylcellulose for versatile applications. Int J Biol Macromol [Internet]. 2020;150:289-303. Available from: https://doi.org/10.1016/j.ijbiomac.2020.01.265

24. Parente ME, Ochoa Andrade A, Ares G, Russo F, Jiménez-Kairuz A. Bioadhesive hydrogels for cosmetic 
applications. Int J Cosmet Sci. 2015;37(5):511-8.

25. Burke KE. Protection From Environmental Skin Damage With Topical Antioxidants. Clin Pharmacol Ther. 2019;105(1):36-8.

26. Yoshino A, Polouliakh N, Meguro A, Takeuchi M, Kawagoe T, Mizuki N. Chum salmon egg extracts induce upregulation of collagen type I and exert antioxidative effects on human dermal fibroblast cultures. Clin Interv Aging. 2016;11:1159-68.

27. Lee KY, Mooney DJ. Alginate: Properties and biomedical applications. Prog Polym Sci. 2012;37(1):106-26.

28. Liu S, Li H, Tang B, Bi S, Li L. Scaling law and microstructure of alginate hydrogel. Carbohydr Polym [Internet]. 2016;135:101-9. Available from: http://dx.doi.org/10.1016/j.carbpol.2015.08.086

29. Poojari R, Srivastava R. Composite alginate microspheres as the next-generation egg-box carriers for biomacromolecules delivery. Expert Opin Drug Deliv. 2013;10(8):1061-76.

30. Patil A, Bhide S, Bookwala M, Soneta B, Shankar V, Almotairy A, et al. Stability of Organoleptic Agents in Pharmaceuticals and Cosmetics. AAPS PharmSciTech. 2018;19(1):36-47.

31. Huang WY, Lee PC, Huang LK, Lu LP, Liao WC. Stability studies of ascorbic acid 2-glucoside in cosmetic lotion using surface response methodology. Bioorganic Med Chem Lett [Internet]. 2013;23(6):1583-7. Available from: http://dx.doi.org/10.1016/j.bmcl.2013.01.111

32. Touloupakis E, Rontogiannis G, Silva Benavides AM, Cicchi B, Ghanotakis DF, Torzillo G. Hydrogen production by immobilized Synechocystis sp. PCC 6803. Int J Hydrogen Energy. 2016 Sep;41(34):15181-6.

33. Terescenco D, Hucher N, Picard C, Savary G. Sensory perception of textural properties of cosmetic Pickering emulsions. Int J Cosmet Sci. 2020;42(2):198-207.

2021 by the authors. Submitted for possible open access publication under the terms and conditions of the Creative Commons Attribution (CC BY NC) license (https://creativecommons.org/licenses/by-nc/4.0/). 